This item was submitted to Loughborough's Research Repository by the author.

Items in Figshare are protected by copyright, with all rights reserved, unless otherwise indicated.

\title{
Effect of breakfast omission on subjective appetite, metabolism, acylated ghrelin and GLP-1(7-36) during rest and exercise
}

PLEASE CITE THE PUBLISHED VERSION

http://dx.doi.org/10.1016/j.nut.2015.06.013

PUBLISHER

(C) Elsevier

VERSION

AM (Accepted Manuscript)

\section{PUBLISHER STATEMENT}

This work is made available according to the conditions of the Creative Commons Attribution-NonCommercialNoDerivatives 4.0 International (CC BY-NC-ND 4.0) licence. Full details of this licence are available at: https://creativecommons.org/licenses/by-nc-nd/4.0/

\section{LICENCE}

CC BY-NC-ND 4.0

\section{REPOSITORY RECORD}

Clayton, David, David Stensel, and Lewis James. 2019. "Effect of Breakfast Omission on Subjective Appetite, Metabolism, Acylated Ghrelin and GLP-1(7-36) During Rest and Exercise”. figshare.

https://hdl.handle.net/2134/20822. 


\section{Accepted Manuscript}

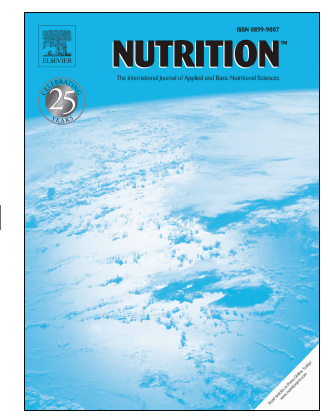

Effect of breakfast omission on subjective appetite, metabolism, acylated ghrelin and GLP-17-36 during rest and exercise

David J. Clayton, David J. Stensel, Lewis J. James

PII: S0899-9007(15)00284-1

DOI: $\quad$ 10.1016/j.nut.2015.06.013

Reference: $\quad$ NUT 9562

To appear in: Nutrition

Received Date: 9 February 2015

Revised Date: 18 June 2015

Accepted Date: 23 June 2015

Please cite this article as: Clayton DJ, Stensel DJ, James LJ, Effect of breakfast omission on subjective appetite, metabolism, acylated ghrelin and GLP-17-36 during rest and exercise, Nutrition (2015), doi: 10.1016/j.nut.2015.06.013.

This is a PDF file of an unedited manuscript that has been accepted for publication. As a service to our customers we are providing this early version of the manuscript. The manuscript will undergo copyediting, typesetting, and review of the resulting proof before it is published in its final form. Please note that during the production process errors may be discovered which could affect the content, and all legal disclaimers that apply to the journal pertain. 
1 Effect of breakfast omission on subjective appetite, metabolism, acylated ghrelin and

$2 \quad$ GLP-1 1-36 during rest and exercise

3 David J. Clayton ${ }^{1}$, David J. Stensel ${ }^{1} \&$ Lewis J. James ${ }^{1} *$

4

$5{ }^{1}$ School of Sport, Exercise and Health Sciences, Loughborough University, Loughborough, $6 \quad$ Leicestershire, LE11 3TU, UK.

7

8

9

$10 *$ Corresponding author: Dr. Lewis J. James

11 Email: L.James@lboro.ac.uk

12 Tel: +44 (0) 1509226305

13 Fax: +44 (0) 1509226301

14

15

16 Running head: breakfast omission, appetite and energy metabolism

17

18 Word count: 4987

19 
20

21

22

\section{Abstract}

Breakfast omission induces compensatory eating behaviour at lunch, but often reduces daily energy intake. This study investigated the effect of breakfast omission on within-day subjective appetite, energy expenditure, substrate utilisation and appetite hormone profiles, in response to standardised feeding and exercise. Eight male, habitual breakfast eaters completed two randomised trials. Subjects arrived overnight fasted $(0 \mathrm{~h})$, and either consumed (BC) or omitted (BO) a standardised breakfast (Mean (SD) (3085 (217) kJ). Lunch $(4162(510) \mathrm{kJ})$ and dinner (4914 (345) kJ) were provided at 4.5 and $10 \mathrm{~h}$, respectively and subjects performed 60 min fixed-intensity cycling $\left(50 \% \mathrm{VO}_{2}\right.$ peak) at $8 \mathrm{~h}$. Blood samples were collected at $0,4.5,6$ and $8 \mathrm{~h}$, with expired air and subjective appetite sensations (hunger, fullness, desire to eat (DTE) and prospective food consumption (PFC)) collected throughout. Heart rate and perceived exertion were measured during exercise. Hunger, DTE and PFC were greater and fullness lower during BO $(P<0.05)$ between breakfast and lunch, with no differences after lunch $(P>0.193)$. Resting energy expenditure was greater at $2.5 \mathrm{~h}$ during $\mathrm{BC}(P<0.05)$ with no other differences between trials $(P>0.156)$. GLP-1 1 -36 was greater $(P<0.05)$ and acylated ghrelin tended to be greater $(P=0.078)$ at $4.5 \mathrm{~h}$ during $\mathrm{BC}$. Heart rate was greater on $\mathrm{BO}(P<0.05)$ during exercise. The results of this laboratorycontrolled study suggest that the effects of breakfast omission are transient and do not extend beyond lunch, even when the negative energy balance created by breakfast omission is sustained via standardised feeding and exercise.

\section{Word Count: 244}

Key words: Breakfast skipping, Energy restriction, Energy balance, Meal omission, Energy expenditure. 
45

46

47

48

49

50

51

52

53

54

55

56

57

60

\section{Introduction}

Obesity is the product of prolonged positive energy balance and has been identified as a risk factor for several chronic diseases [1]. Meal omission is a frequently cited method of controlling energy intake [2]. In the absence of behavioural compensation, refraining from eating at a prescribed mealtime, such as breakfast, will create an energy deficit. It is thought that the appetite regulatory system will counter perturbations in energy balance, with metabolic and behavioural compensatory responses that target both energy intake and expenditure [3]. Part of this response may be due to the regulation of appetite hormones such as acylated ghrelin and GLP-17-36, which have been suggested as biological mechanisms that affect hunger and food intake. Subjective appetite sensations are a valid and reliable method of assessing motivation to eat before and in response to test meals [4], and may also reflect changes in appetite regulatory hormones [5].

Evidence is emerging that energy omitted at breakfast is not fully compensated for over a 24 h period [3,6-8]. Furthermore, it appears that any compensatory eating behaviour is exhibited during the next meal $[3,6]$, and it is currently unclear whether the increased energy intake at this meal suppresses further intake throughout the day, or whether the appetitive effects of breakfast omission are diminished after the initial stimulation of food intake.

Energy expenditure may also be altered in response to fluxes in energy balance due to breakfast omission. In one study energy expenditure was shown to decrease in the morning in response to breakfast omission, but was not different over a $24 \mathrm{~h}$ period [10]. In this study, energy intake at lunch and dinner was increased to account for the energy omitted at breakfast, whereas complete compensation rarely occurs in response to acute breakfast omission [11]. Low intensity physical activity has been shown to reduce in response to chronic breakfast omission [8]. An exercise intervention may have the potential to offset this decrement somewhat, provided the subjective response to exercise and/or adherence is not 
70 affected by breakfast omission. Lifestyle interventions that combine both dietary restriction

71 and exercise have been shown to be more effective for weight management in the long-term

72 [12]; therefore it is important to consider the effect that a given dietary intervention has on

73 physical activity.

74 A more complete understanding of the hormonal and metabolic responses to breakfast 75 omission is warranted. This this study was designed to investigate the appetite and metabolic 76 responses to breakfast omission, with energy intake at lunch and dinner held constant, which

77 has not been previously investigated. Therefore, the aim of this study was to investigate the

78 effect of breakfast omission on subjective appetite sensations and metabolism in response to 79 standardised feeding and sub-maximal exercise. 
80

81

82

83

84

85

86

87

88

89

90

91

92

93

94

95

96

97

98

\section{Methods}

Subjects

Eight healthy, recreationally active males (age: 27 (6) y; weight: 75 (8.1) kg; height: 1.74 (0.07) m; BMI: 25 (2) $\mathrm{kg} \cdot \mathrm{m}^{-2}$; body fat: 18 (3) \%; $\mathrm{VO}_{2}$ peak: $53.4(5.1) \mathrm{mL} \cdot \mathrm{kg}^{-1}$ (mean (SD)) volunteered to participate in the study. All subjects were regular breakfast eaters, reported to have been weight stable for 6 months, and were not restrained, disinhibited or hungry eaters [13]. The study was approved by the Loughborough University Ethics Approvals (Human Participants) Sub-committee, and all subjects provided full written consent and completed a health screen questionnaire prior to participation.

\section{Preliminary trial}

Subjects' height (Seca, Birmingham, UK), weight (Adam AFW-120K, Milton Keynes, UK) and body fat percentage [14] were determined. Cycling $\mathrm{VO}_{2}$ peak was determined using a discontinuous incremental exercise test (Lode Corival, Groningen, Holland). Increments lasted 4 min, were separated by $\sim 5$ min rest, and work load was increased until volitional exhaustion. Expired air was collected into a Douglas bag during the final min of each stage, with heart rate (Polar Beat, Kemple, Finland) and rating of perceived exertion (RPE) [15] recorded at the end of each increment.

\section{Pre-trial standardisation}

Dietary intake and physical activity in the $48 \mathrm{~h}$ preceding the first experimental trial were recorded by each subject in a diary and these patterns were replicated in the $48 \mathrm{~h}$ before the next trial. Subjects also abstained from alcohol and strenuous exercise during this period.

\section{Protocol}

Subjects completed two experimental trials; breakfast consumption (BC) and breakfast omission (BO). Trials were separated by at least 7 days, conducted at the same time of day, on the same day of the week and administered in a randomised, counterbalanced order. 
105 Subjects travelled to the laboratory via motorised transport arriving at approximately 08:00,

106 following at least a $10 \mathrm{~h}$ fast, and were weighed nude. After $30 \mathrm{~min}$ supine rest $(0 \mathrm{~h})$, blood

107 and expired air samples were collected. Subjective appetite sensations were then assessed on

108 a visual analogue scale (VAS) before subjects consumed either a standardised breakfast (BC)

109 or no breakfast (BO). Subjects then rested quietly in the laboratory. At $4.5 \mathrm{~h}$, a blood sample

110 was collected, before a standardised lunch was consumed. Subjects again rested in the

111 laboratory with blood samples collected at $6 \mathrm{~h}$ and $8 \mathrm{~h}$. Subjects then completed $60 \mathrm{~min}$

112 cycling at 50\% $\mathrm{VO}_{2}$ peak (8-9 h). Heart rate and $\mathrm{RPE}$ were recorded after 20, 40 and $60 \mathrm{~min}$

113 of exercise. One hour after exercise $(10 \mathrm{~h})$ a standardised dinner meal was consumed.

114 Subjects then left the laboratory, but were not permitted to eat until the following morning,

115 completing VAS scales at $12,13.5$ and $24 \mathrm{~h} .$.

116 Standardised meals

117 During BC subjects were provided a standardised breakfast of $25 \%$ estimated daily energy

118 requirements (DER), determined by multiplying resting metabolic rate (RMR) [16] by a

119 physical activity level of 1.7. Breakfast consisted of crisped rice cereal, semi-skimmed milk,

120 white bread, butter, strawberry jam and orange juice (Tesco, Cheshunt, UK). During BO,

121 subjects ingested water $(624(44) \mathrm{mL})$ to match water contained in the breakfast of BC.

122 Subjects were provided the same lunch and dinner on both trials. Lunch consisted of ham

123 sandwiches, crisps and yoghurt (35\% DER) and dinner consisted of pasta, tomato sauce,

124 cheese and olive oil (40\% DER). Subjects consumed each meal gradually over a $30 \mathrm{~min}$

125 period (Table 1).

126 After breakfast, subjects ingested $45 \mathrm{~mL} \cdot \mathrm{kg}^{-1}$ body mass water on each trial $(2318(284) \mathrm{mL})$.

127 This water was distributed so that $100 \mathrm{~mL}$ was provided every $20 \mathrm{~min}$ during exercise. Of the

128 remaining water, 25\% was ingested at lunch and dinner, and $12.5 \%$ at 2.5, 7, 12 and $13.5 \mathrm{~h}$.

129 Subjective appetite sensations 
Hunger, fullness, desire to eat (DTE) and prospective food consumption (PFC) were assessed on $100 \mathrm{~mm}$ VAS at $0,0.5,1.5,2.5,3.5,4.5,5,6,7,8,9,10,10.5,12,13.5,24 \mathrm{~h}$. Verbal anchors of 'not at all/no desire at all/none at all' and 'extremely/a lot' were placed at 0 and

$133100 \mathrm{~mm}$, respectively.

\section{Expired air samples}

135 Ten min expired air samples were collected at $0,2.5,4.5,6,8$ and $10 \mathrm{~h}$ in a supine position after $20 \mathrm{~min}$ supine rest [17]. The first $5 \mathrm{~min}$ was discarded and the second $5 \mathrm{~min}$ was collected into a Douglas bag. $\mathrm{O}_{2}$ and $\mathrm{CO}_{2}$ concentration were determined using a 138 paramagnetic oxygen analyser and an infra-red carbon dioxide analyser, respectively (1400

139 Series, Servomex, East Sussex, UK). These were calibrated prior to each sample using 140 certified reference gases (BOC, Guildford, UK). The volume (Harvard Dry Gas Meter, 141 Harvard Ltd, Kent, UK) and temperature (Edale thermister, Cambridge, UK) of each expired 142 air sample were also determined. Energy expenditure and substrate oxidation were calculated 143 using the stoichiometric equations described by Frayn [18]. Four min expired air samples 144 were collected after 20, 40 and 60 min of exercise, of which the first 2 min of each sample 145 was discarded.

146 Blood sampling and analysis

147 Blood samples (12 mL) were drawn after $30 \mathrm{~min}$ supine rest, at $0,4.5,6$ and $8 \mathrm{~h}$ via 148 venepuncture of an antecubital vein. Five $\mathrm{mL}$ blood was immediately mixed with $50 \mu \mathrm{L}$ 149 Dipeptidyl-peptidase 4 inhibitor (DPP4-010, Merck Millipore, Watford, UK) and dispensed 150 into an EDTA tube $\left(1.75 \mathrm{mg} \cdot \mathrm{mL}^{-1}\right)$, for determination of active glucagon-like peptide-1 151 (GLP-17-36) by ELISA (EGLP-35K, Merck Millipore, Watford, UK). Two and a half mL 152 blood was dispensed into an EDTA tube containing $10 \mu \mathrm{L} \cdot \mathrm{mL}^{-1}$ of a potassium phosphate 153 buffer (PBS) (0.05 M), P-hydroxymercuribenzonic acid (PHMB) (0.05 M) and sodium 154 hydroxide solution $(\mathrm{NaOH})(0.006 \mathrm{M})$ for determination of acylated ghrelin concentration by 
155 ELISA (A05106, Bioquote Ltd, York, UK). Two and a half $\mathrm{mL}$ of blood was dispensed into an EDTA tube for measurement of blood glucose concentration (GOD-PAP method, Randox Laboratories Ltd, Crumlin, UK) and insulin concentration by ELISA (DX-EIA-2935,

158 Immunodiagnostic Systems, Boldon, UK).

159 All samples were centrifuged at $1750 \mathrm{~g}$ for a total of $15 \mathrm{~min}$ in a refrigerated centrifuge $\left(4^{\circ} \mathrm{C}\right)$.

160 After $10 \mathrm{~min}$ of centrifugation, the supernatant $(1 \mathrm{~mL})$ of the $\mathrm{PHMB} / \mathrm{PBS} / \mathrm{NaOH}$ treated 161 blood was combined with $100 \mu \mathrm{L} \cdot \mathrm{mL}^{-1} \mathrm{HCl}(1 \mathrm{M})$ before all samples were centrifuged for a 162 further $5 \mathrm{~min}$. The supernatant of each sample was then removed and stored at $-20^{\circ} \mathrm{C}$ until 163 frozen and then transferred to $-80^{\circ} \mathrm{C}$ for later analysis.

164 A further $2 \mathrm{~mL}$ blood was collected into an EDTA tube and used for the determination of 165 haemoglobin (via the cyanmethaemoglobin method) and haematocrit (via micro166 centrifugation), and used to estimate changes in plasma volume relative to baseline [19].

\section{Statistical Analysis}

168 Data was analysed using SPSS 21.0 (SPSS Inc., Somers, NY, USA). Area under the curve 169 (AUC) values were calculated using the trapezoidal method and averaged over time. 170 Subjective appetite sensations were then separated into three periods $(0-4.5 \mathrm{~h}, 5-10 \mathrm{~h}, 10.5-24$ h) and energy expenditure was presented as total $(0-10 \mathrm{~h})$, and also divided into two time

172 periods $(0-4.5 \mathrm{~h}, 5-10 \mathrm{~h})$. Correction of hormone concentrations for plasma volume change 173 did not alter the results so the unadjusted values are presented. All data were checked for 174 normality of distribution using a Shapiro-Wilk test. Data containing one factor were analysed 175 using a t-test or Wilcoxon signed-rank test, as appropriate. Data containing two factors were 176 analysed using a two-way repeated measures ANOVA, followed by post-hoc Bonferroni177 adjusted paired t-tests or Bonferroni-adjusted Wilcoxon signed-ranks, as appropriate. Data 178 sets were determined to be significantly different when $P<0.05$. Data are presented as mean 179 (SD) unless otherwise stated. 
180

181

182

183

184

185

186

187

188

189

190

191

192

193

194

195

196

197

198

199

200

201

202

203

\section{Results}

Pre-trial values

Pre-trial body mass $(P=0.155)$, subjective appetite sensations (all $P>0.346), \operatorname{RMR}(P=0.393)$, carbohydrate oxidation $(P=0.815)$ and fat oxidation $(P=0.290)$ were not different between trials. Plasma concentrations of glucose $(P=0.512)$, insulin $(P=0.488)$, acylated ghrelin $(P=0.526)$ and $\operatorname{GLP}-1_{7-36}(P=0.636)$ were also not different between trials at baseline.

\section{Subjective appetite sensations}

All subjective appetite sensations showed an interaction effect $(P<0.001)$. Sensations of fullness were lower concurrent with greater hunger, DTE (all $P<0.01$ ) and a tendency for greater PFC $(P=0.078)$ at $0.5 \mathrm{~h}$ during BO compared to BC. Between 1.5 and $3.5 \mathrm{~h}$, lower fullness and greater hunger, DTE and PFC (all $P<0.05)$ was observed during BO compared to BC. Lower hunger $(P<0.01)$, PFC $(P<0.05)$ and a tendency for lower DTE $(P=0.078)$ was found immediately prior to lunch $(4.5 \mathrm{~h})$ during $\mathrm{BC}$ compared to $\mathrm{BO}$, but there was no difference between trials for fullness $(P=0.234)$. After lunch there were no differences between trials for any appetite variables $(5.5-24 \mathrm{~h})(P>0.125$; Fig 1$)$.

Data was divided into 3 sections for AUC analysis; baseline to lunch (0-4.5 h), post-lunch to dinner $(5-10 \mathrm{~h})$ and post-dinner (10.5-24 h). These analyses revealed differences between trials for all appetite variables between baseline and lunch (all $P<0.05$ ), with no further differences between trials (all $P>0.719$; Fig 1).

\section{Energy expenditure and substrate oxidation}

Due to a fault with the gas collection equipment during one trial for one subject, this subjects air samples were removed from the analysis. Therefore data from 7 subjects is presented.

Respiratory exchange ratio $($ RER) showed an interaction effect $(P<0.05)$ and was greater at $2.5(P<0.01), 4.5(P<0.05)$ and $10 \mathrm{~h}(P<0.05)$ during $\mathrm{BC}$ compared to BO (Fig 2a). 
204 Carbohydrate oxidation was greater at $2.5(P<0.001)$ and $4.5 \mathrm{~h}(P<0.05)$ during BC, but fat

oxidation was not different between trials $(P=0.413)$.

206 There was an interaction effect for energy expenditure $(P<0.01)$, with greater energy 207 expenditure at $2.5 \mathrm{~h}$ during $\mathrm{BC}(P<0.05)$ compared to $\mathrm{BO}$, with no other differences between 208 trials $(P>0.156$; Fig 2 b). AUC analyses revealed a tendency for increased energy expenditure 209 at $0-4.5 \mathrm{~h}(P=0.066)$ during $\mathrm{BC}$, but no difference at $5-10 \mathrm{~h}(P=0.523)$ or in total $(P=0.193)$.

\section{Blood parameters}

211 Plasma acylated ghrelin concentrations showed a main effect of time $(P<0.001)$, but no 212 interaction effect $(P=0.238)$. Bloxplot analysis revealed one consistently outlying subject 213 within the data set, exhibiting acylated ghrelin concentrations $\sim 11$ standard deviations greater 214 than the mean of the 7 other subjects. Therefore, this subject was removed from the analysis. 215 After removal, an interaction effect was identified $(P<0.05)$. Acylated ghrelin tended to be 216 higher during BC compared to BO at $4.5 \mathrm{~h}(P=0.078)$. Compared to $0 \mathrm{~h}$, acylated ghrelin was 217 greater at $4.5 \mathrm{~h}$ during $\mathrm{BC}(P<0.05)$ and reduced at $6 \mathrm{~h}$ during $\mathrm{BO}(P<0.05)$ (Table 2$)$.

218 An interaction effect $(P<0.05)$ was identified for GLP-1 ${ }_{7-36}$, with greater concentrations at 4.5

$219 \mathrm{~h}$ during $\mathrm{BC}$ compared to $\mathrm{BO}(P<0.05)$. Compared to baseline, GLP-1 $1_{7-36}$ was greater at 6 and $2208 \mathrm{~h}$ during $\mathrm{BC}$ and at $8 \mathrm{~h}$ during $\mathrm{BO}(P<0.05$; Table 2$)$

221 Plasma insulin showed a main effect of time $(P<0.001)$ and was greater than baseline at $6 \mathrm{~h}$ 222 during $\mathrm{BC}(P<0.05)$ as well as at 6 and $8 \mathrm{~h}$ during $\mathrm{BO}(P<0.05)$. No interaction effect was 223 observed for plasma insulin $(P=0.468)$ or glucose $(P=0.067)$ concentration (Table 2$)$.

\section{Exercise responses}

225 There was a main effect of trial for heart rate $(P<0.05)$, which was elevated at 60 min during $226 \mathrm{BO}$ compared to $\mathrm{BC}(P<0.05)$, and tended to be elevated at $40 \mathrm{~min}(P=0.068) . \mathrm{VO}_{2}$ $227(P=0.503)$, RER $(P=0.135)$, carbohydrate oxidation $(P=0.143)$, fat oxidation $(P=0.143)$, 228 energy expenditure $(P=0.289)$ and $\operatorname{RPE}(P=0.129)$ were similar between trials (Table 3$)$. 


\section{Discussion}

230 This investigation found that subjective appetite sensations, appetite hormones and energy

231 expenditure were not different after lunch, regardless of whether the subject consumed or

232 omitted breakfast. Therefore, it appears that the appetitive and metabolic effects of breakfast

233 omission are transient and might be offset by a standardised lunch. Breakfast omission also

234 does not influence perception of effort or energy expenditure during $60 \mathrm{~min}$ of steady-state

235 cycling exercise performed $3 \mathrm{~h}$ after lunch. This data suggests that occasional breakfast

236 omission may not stimulate appetite and promote energy intake as has been previously

237 inferred (20).

238 Regularity of breakfast consumption has been identified as a risk factor for obesity, with

239 correlational evidence to suggest that habitual breakfast consumers have a lower BMI than

240 breakfast omitters [20]. However, habitual breakfast consumers also tend to exhibit healthy

241 lifestyle practices, such as greater levels of physical activity [21] and improved dietary

242 profiles [22] than breakfast omitters, making causal mechanisms difficult to elucidate. Acute

243 studies that have directly manipulated the consumption or omission of breakfast have

244 generally reported that the omission of breakfast will increase appetite and induce

245 compensatory eating behaviour at lunch [6,9]. Whilst one study found that the energy omitted

246 at breakfast was fully compensated for at an ad-libitum lunch meal [23], the majority of

247 studies have reported that energy intake at a single meal [6,9,24] or over a $24 \mathrm{~h}$ period [3,6-8]

248 is rarely sufficient to fully compensate for the energy omitted at breakfast. In the current

249 investigation, the energy consumed at each meal was fixed so an increase in energy intake

250 could not occur. These results demonstrate that even when energy consumed at lunch is

251 controlled, there were no differences in appetite sensations or concentrations of acylated

252 ghrelin and GLP-1 $1_{(7-36)}$ after lunch. 
253 The transient suppression of appetite after consumption compared to omission of breakfast

254 has previously been observed after an ad-libitum lunch meal, which was used to gauge

255 voluntary food intake [6,9]. However, the present investigation has demonstrated that

256 appetite in the post-lunch period can be offset by an absolute energetic load, as opposed to

257 subjects eating to satiation. This effect was shown to persist throughout the rest of the day,

258 despite subjects consuming $\sim 3000 \mathrm{~kJ}$ less during BO. Therefore, controlling food intake at

259 subsequent meals does not appear to affect the appetitive response to acute breakfast

260 omission, and this could allow greater energy deficits to be achieved, compared to when ad-

261 libitum meals are consumed. However, it should be noted that subjective appetite sensations

262 do not always accurately predict subsequent food intake [25].

263 Energy expenditure increased at $2.5 \mathrm{~h}$ during BC, compared to BO. This would be anticipated 264 due to dietary induced thermogenesis (DIT). The thermogenesis associated with feeding is 265 dependent on the energetic load and the macronutrient content of the meal. When the 266 breakfast meal was broken down into its constituents, the estimated DIT of the meal was 267 approximately $9.8 \%$ of the total energy content of the meal, which is in line with the typically 268 reported DIT of a mixed meal of $10 \%$ [26]. Taking this into account, it is likely that the 269 majority of the post-prandial increase in energy expenditure at $2.5 \mathrm{~h}$ was due to an increase in

270 DIT. Even including DIT in the morning, AUC analysis did not reveal any differences

271 between trials over the $10 \mathrm{~h}$ expired air sampling period. This is in line with the finding of

272 Kobayashi et al. [10] who reported that breakfast consumption increased energy expenditure

273 in the morning, compared to breakfast omission, but $24 \mathrm{~h}$ energy expenditure was not 274 different between trials. In this study, the energy content of the lunch and dinner meals were 275 increased in the no breakfast condition to match total daily energy intake between trials. The 276 results of the current study have therefore extended those of Kobayashi et al. [10] and 
277 determined that, even in an energy deficient state, energy expenditure is not affected by 278 occasional breakfast omission.

279 The nature of measuring energy expenditure in a laboratory requires the subject to be at rest, 280 and therefore changes in habitual activity patterns may have been overlooked. Betts et al. [8] 281 found that over a 6 week period, breakfast omission decreased habitual energy expenditure 282 by $\sim 1850 \mathrm{~kJ} \cdot \mathrm{d}^{-1}$ compared to when breakfast was consumed. This was attributed to a decrease in low intensity physical activity, as opposed to a reduction in exercise intensity/duration, which was not measured in the current investigation. It is possible that physical activity of this nature is subconsciously affected by breakfast omission. Results of the present study show that any reduction in energy expenditure is not due to changes in resting metabolism, and therefore the incorporation of exercise into daily routines may help offset this reduction in low intensity physical activity, provided adherence to exercise is not affected by the dietary intervention.

290 Time constraints of a working lifestyle often restrict time to exercise to the morning or 291 evening, with evening exercise classes associated with increased alertness and enthusiasm, as 292 well as being deemed to require less effort than morning classes [27]. This may help improve 293 adherence to an exercise program in the long term. The current study implemented a 294 prescribed exercise protocol on both experimental trials, and found that heart rate was 295 elevated during exercise on BO compared to BC. This suggests that subjects were more 296 physiologically challenged during exercise on BO, although this was not reflected in RPE, $297 \mathrm{VO}_{2}$ or energy expenditure. Digestion and absorption of nutrients from the gut is a process that requires oxygen to be delivered to the splanchnic tissue, typically achieved via a redistribution of blood away from the skeletal muscle or an increase in cardiac output [28].

300 During exercise, where the skeletal muscle requirements for oxygen are high, an increase in 301 heart rate would facilitate meeting the metabolic requirements of skeletal muscle activity and 
digestion and absorption of nutrients. Heart rate may have been increased to a greater extent during exercise on $\mathrm{BO}$, as splanchnic blood supply for digestion and absorption of nutrients may be prioritised, due to the subjects peripheral fuel supply being reduced during BO compared to $\mathrm{BC}$ [29]. Noradrenaline is an indicator of peripheral sympathetic nervous activity, and has been shown to peak after breakfast, and progressively decline following lunch and dinner meals [30]. By removing breakfast during BO, it is possible that the peak sympathetic response occurred after lunch, which subsequently increased heart rate to a greater extent during exercise on $\mathrm{BO}$.

The increase in appetite over the morning period during BO has been suggested to lead to the consumption of energy dense snacks [31], and indeed an increase in snacking behaviour has been observed in a previous study [3]. Elevated levels of the appetite stimulating hormone ghrelin and suppression of satiety hormones, such as GLP-1, have been suggested as

314 biological mechanisms that stimulate hunger and promote food intake [5,32]. In the present study, GLP-1 $1_{7-36}$ was suppressed immediately prior to lunch in BO compared to BC, which may be linked to greater fullness and lower hunger, DTE and PFC in the present study,

317 following breakfast consumption. Interestingly, acylated ghrelin tended to be higher prior to 318 lunch during $\mathrm{BC}$ compared to $\mathrm{BO}(P=0.078)$. The reason for this is unclear; however ghrelin 319 has been shown to respond diurnally, peaking at anticipated meal times. Extending the 320 overnight fast during BO may have affected this diurnal variation, which may be governed 321 primarily by post-prandial decreases rather than pre-prandial increases [33]. After lunch, 322 there were no differences in acylated ghrelin and GLP- $1_{(7-36)}$ suggesting, in line with the subjective appetite sensations, there was no additional desire to increase food intake after 324 lunch.

325 In conclusion, this laboratory-controlled investigation found that subjective appetite 326 sensations, acylated ghrelin, GLP-1 $1_{(7-36)}$ and resting energy expenditure were not different, 
327 independent of whether breakfast was consumed or omitted. This was found in spite of 328 sustaining the negative energy balance induced by breakfast omission, via standardised lunch

329 and dinner feeding and a prescribed exercise protocol. Consuming breakfast in the morning 330 appears to only transiently suppress appetite compared to when breakfast is omitted, and 331 appetite can be offset with provision of a standardised lunch meal. This extends findings from 332 ad-libitum feeding studies, and suggests that a similar effect can be achieved with a 333 standardised lunch meal, which may help enhance the energy deficit that can be achieved. 334 Therefore, this study supports occasional breakfast omission as a means to reduce daily 335 energy intake. 


\section{Acknowledgements}

339 This research was supported by the National Institute for Health Research (NIHR) Diet,

340 Lifestyle \& Physical Activity Biomedical Research Unit based at University Hospitals of

341 Leicester and Loughborough University. The views expressed are those of the authors and

342 not necessarily those of the NHS, the NIHR or the Department of Health. Study conception,

343 design, data collection and analysis were conducted by DJC and LJJ. The manuscript was

344 written by DJC, with assistance from LJJ and DJS. All authors approved the final manuscript. 


\section{References}

1. Wyatt HR, Grunwald GK, Mosca CL, Klem ML, Wing RR, Hill JO. Long term weight loss and breakfast in subjects in the national weight control registry. Obes Res. $2002 ; 10(2): 78-82$

2. Zullig K, Ubbes VA, Pyle J, Valois RF. Self-reposted weight perceptions, dieting behavior and breakfast eating among high school adolescents. Br Heart J. 1990; 63(3):87-92.

3. Martin A, Norman S, Sothier M, Peyrat J, Louche-Pelissier C, Laville M. Is advice for breakfast consumption justified? Results from a short-term dietary and metabolic experiment in young healthy men. Br J Nutr. 2000; 84(3)337-44.

4. Flint A, Raben A, Blundell JE, Astrup A. Reproducibility, power and validity of visual analogue scales in assessment of appetite sensations in single test meal studies. Int J Obes Relat Metab Disord. 2000; 24(1):38-48.

5. Cummings DE. Ghrelin and the short- and long-term regulation of appetite and body weight. Physiol Behav. 2006; 89(1):71-84.

6. Levitsky DA, Pacanowski CR. Effect of skipping breakfast on subsequent energy intake. Physiol Behav. 2013; 119:9-16.

7. Reeves S, Huber JW, Halsey LG, Horbady-Farahani Y, Ijadi M, Smith T. Experimental manipulation of breakfast in normal and overweight/obese participants is associated with changes to nutrient and energy intake consumption patterns. Physiol Behav. 2014; 133:130-5.

8. Betts JA, Richardson JD, Chowdhury EA, Holman GD, Tsintzas K, Thompson D. The causal role of breakfast in enrgy balance and health: A randomised controlled trial in lean adults. Am J Clin Nutr. 2014; 100(2):539-47. 
9. Hubert P, King NA, Blundell JE. Uncoupling the effects of energy expenditure and energy intake: appetite response to short-term energy deficit induced by meal omission and physical activity. Appetite. 1998; 31(1):9-19.

10. Kobayashi F, Ogata H, Omi N, Nagasaka S, Ysmsguchi S, Hibi M et al. Effect of breakfast skipping on diurnal variation of energy metabolism and blood glucose. Obes Res Clin Pract. 2014; 8(3):e201-98.

375

11. Levitsky DA. Next will be apple pie. Am J Clin Nutr. 2014; 100(2):503-504.

12. Franz MJ, VanWormer JJ, Crain AL, Boucher JL, Histon T, Caplan W et al. Weightloss outcomes: a systematic review and meta-analysis of weight-loss clinical trials with a minimum 1-year follow-up. J Am Diet Assoc. 2007; 107(10):1755-67.

13. Stunkard AJ, Messick S. The three-factor eating questionnaire to meaasure dietary restraint, disinhibition and hunger. J Psychosomatic Res. 1985; 29(I):71-83.

14. Durnin JVGA, Womersley J. Body fat assessed from total body density and its estimation from skinfold thickness: measurements on 481 men and women aged from 16 to 72 Years. Br J Nutr.1974; 32(01):77-97.

15. Borg G. Percieved exertion. A note on "history" a methods. Med Sci Sports. 1973; $5(2): 90-3$.

16. Mifflin MD, St Jeor ST, Hill LA, Scott BJ, Daugherty SA, Koh YO. A new predictive equation in healthy individuals for resting energy. Am J Clin Nutr. 1990; 51:241-7.

17. Compher C, Frankenfield D, Keim N, Roth-Yousey L. Best practise methods to apply to measurement of resting metabolic rate in adults: a systematic review. J Am Diet Assoc. 2006; 106(6):881-903.

18. Frayn, K N. Calculation of substrate oxidation rates in vivo from gaseous exchange. $J$ Appl Physiol. 1983; 55(2):628-34. 
19. Dill DB, Costill DL. Calculation of percentage changes in volumes of blood, plasma, and red cells in dehydration. J Appl Physiol. 1974; 37(2):247-8.

20. Cho S, Dietrich M, Brown CJP, Clark CA, Block G. The effect of breakfast type on total daily energy intake and body mass index: results from the Third National Health and Nutrition Examination Survey (NHANES III). J Am Coll Nutr. 2003; 22(4):296302.

21. Cohen B, Evers S, Manske S, Bercovitz K, Edward HG. Smoking, physcal activity and breakfast consumption among secondary school students in a southwestern Ontario community. Canadian J Public Heal. 2003; 94(1):41-4. consumption on adequacy of micronutrient intakes and compliance with dietary recommendations in Irish adults. Public Health Nutr. 2003; 6(4):351-63.

23. Astbury NM, Taylor MA, Macdonald IA. Breakfast consumption affects appetite, energy intake, and the metabolic and endocrine responses to foods consumed later in the day in male habitual breakfast eaters. J Nutr. 2011; 141(7):1381-9.

24. Gonzalez JT, Veasey RC, Rumbold PLS, Stevenson EJ. Breakfast and exercise contingently affect postprandial metabolism and energy balance in physically active males. Br J Nutr. 2013; 110(4):721-32.

25. Clayton DJ, Stensel DJ, Watson P, James LJ. The effect of post exercise drink macronutrient content on appetite and energy intake. Appetite. 2014; 82:173-9 of a single exercise class on appetite, energy intake and mood. Is there a time of day effect? Appetite. 2005; 45(3):272-8. 
417

418

419

420

421

422

423

424

425

426

427

428

429

430

431

432

433

28. Yi JJ, Fullwood L, Stainer K, Cowley AJ, Hampton JR. Effects of food on the central and peripheral haemodynamic response to upright exercise in normal volunteers. $\mathrm{Br}$ Heart J. 1990; 63(1):22-5.

29. Van Baak MA. Meal-induced activation of the sypathetic nervous system and its cardiovascular and thermogenic effects in man. Physiol Behav. 2008; 94:178-86

30. Panev P, Spiegel K, Marcinkowski T, Van Cauter E. Impact of carbohydrate-rich meals on plasma epinephrine levels: dysregulation with aging. J Clin Endocrinol Metab. 2005; 90(11):6198-206.

31. O'Connor DB, Conner M, Jones F, McMillan B, Ferguson E. Exploring the benefits of conscientiousness: an investigation of the role of daily stressors and health behaviours. Ann Behav Med. 2009; 37(2):184-96

32. Holst JJ. The physiology of glucagon-like peptide 1. Physiol Rev. 2007; 87(4):1409_ 39.

33. Chan JL, Bullen J, Lee JH, Yiannakouris N, Mantzoros CS. Ghrelin levels are not regulated by recombinant leptin administration and/or three days of fasting in healthy subjects. J Clin Endocrinol Metab. 2004; 89(1):335-43 
434 Captions (Figures 1 \& 2)

435

436 Figure 1. Subjective feelings of hunger (A), fullness (B), desire to eat (C) and prospective

437 food consumption (D) (left panel) and AUC analysis (right panel) during BC (匹) and BO (口).

438 Data are mean (SE) for the left panel and mean (SD) right panel. White rectangle indicates

439 breakfast, hatched rectangles indicate standard meals, black rectangle represents exercise. ${ }^{\dagger}$

440 Significantly different to $\mathrm{BC}(P<0.05)$.

441

442 Figure 2. Respiratory exchange ratio (RER) during BC (匹) and BO ( $\square$ ) (A); and Resting

443 energy expenditure (B). Data are mean (SD). On x-axis, white rectangle indicates breakfast,

444 hatched rectangle indicates standard meal, black rectangle represents exercise. ${ }^{\dagger}$ Significantly

445 different to BC $(P<0.05)$; * Significantly different to baseline $(P<0.05)$.

446 
447 Tables with captions

448 Table 1. Energy and macronutrient intake. Values are mean (SD).

\begin{tabular}{|c|c|c|c|c|c|}
\hline & CHO (g) & PRO (g) & FAT (g) & FIBRE (g) & ENERGY (kJ) \\
\hline \multicolumn{6}{|c|}{ Breakfast } \\
\hline BC & $130.0(9.1)$ & $19.5(1.4)$ & $13.7(1.0)$ & $4.5(0.3)$ & 3085 (217) \\
\hline BO & 0 & 0 & 0 & 0 & 0 \\
\hline \multicolumn{6}{|c|}{ Lunch } \\
\hline $\begin{array}{l}\text { BC } \\
\text { BO }\end{array}$ & $118.9(8.3)$ & $38.6(2.7)$ & $41.1(2.9)$ & $12.0(0.8)$ & $4162(301)$ \\
\hline \multicolumn{6}{|c|}{ Dinner } \\
\hline $\begin{array}{l}\text { BC } \\
\text { BO }\end{array}$ & $150.6(10.5)$ & $41.2(2.9)$ & $43.2(3.0)$ & $6.8(0.5)$ & 4914 (345) \\
\hline BC & $399.6(28.0)$ & $99.4(7.0)$ & $94.4(13.0)$ & $23.2(1.6)$ & $12162(988)$ \\
\hline BO & $270.0(18.9)$ & $79.9(5.6)$ & 80.7 (12.3) & $18.8(1.3)$ & 9077 (789) \\
\hline
\end{tabular}

449

450 
451 Table 2. Plasma concentrations of acylated ghrelin, GLP-1 ${ }_{7-36}$, insulin and glucose. Data are

452 mean (SD). ${ }^{\dagger}$ Significantly different to $\mathrm{BC} ; *$ Significantly different to baseline $(P<0.05)$.

\begin{tabular}{|c|c|c|c|c|}
\hline & $\mathbf{O} \mathbf{h}$ & $4.5 \mathrm{~h}$ & $6 \mathrm{~h}$ & $8 \mathrm{~h}$ \\
\hline \multicolumn{5}{|c|}{ Acylated Ghrelin $\left(\mathrm{pg} \cdot \mathrm{mL}^{-1}\right)$} \\
\hline BC & $162(132)$ & $213(147)^{*}$ & 114 (132) & $156(150)$ \\
\hline BO & $168(150)$ & $178(171)$ & $111(148)^{*}$ & $150(165)$ \\
\hline \multicolumn{5}{|c|}{ GLP-1 $_{7-36}(\mathbf{p M})$} \\
\hline BC & $9.67(8.49)$ & $10.13(8.22)$ & $12.34(7.67)^{*}$ & $11.72(8.32)^{*}$ \\
\hline BO & $9.92(9.78)$ & $8.52(8.83)^{\dagger}$ & $13.01(7.92)$ & $12.85(8.88)^{*}$ \\
\hline \multicolumn{5}{|c|}{ Insulin $\left(\mu \mathrm{IU} \cdot \mathbf{m L}^{-\mathbf{1}}\right)$} \\
\hline BC & $9.56(4.29)$ & $7.03(3.98)$ & $30.09(11.68)^{*}$ & $18.49(8.67)$ \\
\hline BO & $8.74(3.90)$ & $7.56(3.35)$ & $34.90(15.86)^{*}$ & $15.58(3.78)^{*}$ \\
\hline \multicolumn{5}{|c|}{ Glucose $\left(\mathbf{m m o l} \cdot \mathbf{L}^{-1}\right)$} \\
\hline BC & $5.33(0.22)$ & $4.77(0.42)$ & $5.28(0.79)$ & $5.17(0.45)$ \\
\hline BO & $5.35(0.23)$ & $5.26(0.47)$ & $5.69(0.88)$ & $4.88(0.56)$ \\
\hline
\end{tabular}

453

454 
455 Table 3. Variables collected during exercise. Data are mean (SD). ${ }^{\dagger}$ Significantly different to $456 \mathrm{BC}(P<0.05)$.

\begin{tabular}{cccc}
\hline & BC & BO & $P$-value \\
\hline $\mathrm{VO}_{2}\left(\mathrm{~L} \cdot \mathrm{min}^{-1}\right)$ & $1.95(0.25)$ & $1.92(0.26)$ & 0.503 \\
RER & $0.92(0.03)$ & $0.90(0.01)$ & 0.107 \\
Carbohydrate oxidation $\left(\mathrm{g} \cdot \mathrm{min}^{-1}\right)$ & $1.93(0.34)$ & $1.72(0.14)$ & 0.143 \\
Fat oxidation $\left(\mathrm{g} \cdot \mathrm{min}^{-1}\right)$ & $0.25(0.14)$ & $0.31(0.08)$ & 0.143 \\
Energy Expenditure $\left(\mathrm{kJ} \cdot \mathrm{min}^{-1}\right)$ & $42.05(5.01)$ & $40.78(5.16)$ & 0.289 \\
Heart rate $\left(\right.$ beats $\left.\cdot \mathrm{min}^{-1}\right)$ & $130(5)$ & $134(6)^{\dagger}$ & 0.032 \\
RPE & $11(1)$ & $12(1)$ & 0.129 \\
\hline
\end{tabular}


A

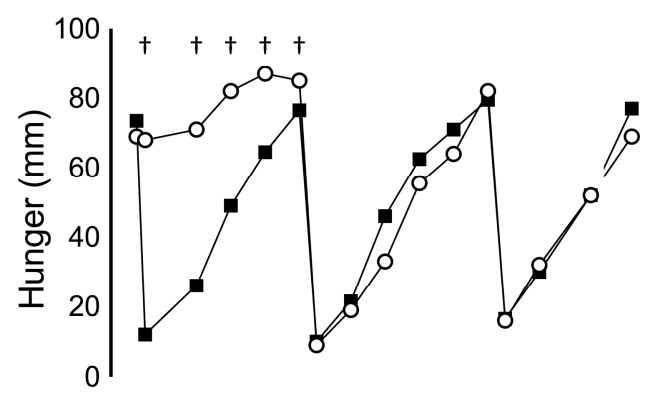

B

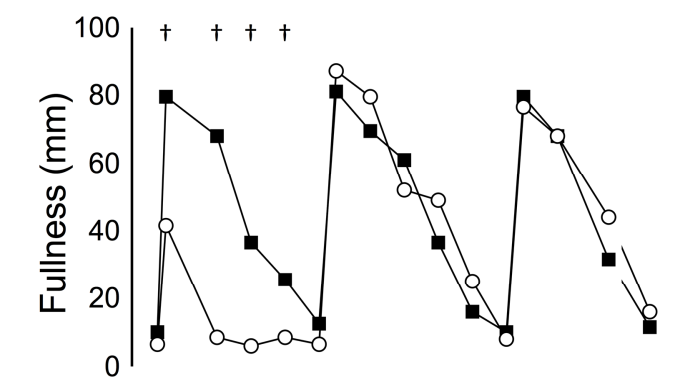

C

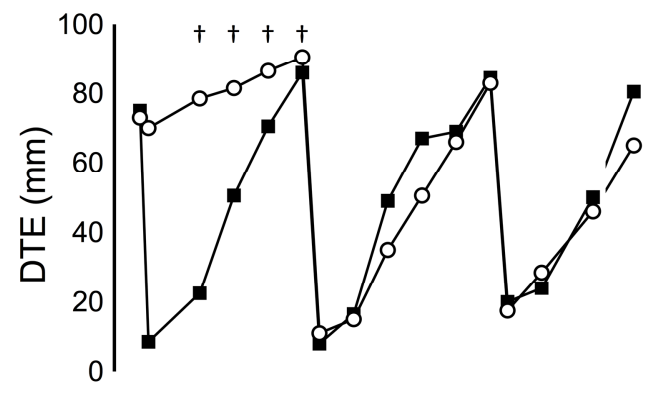

D

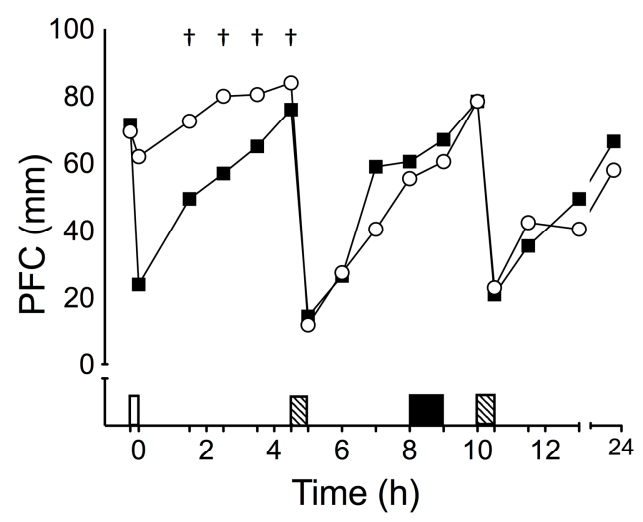

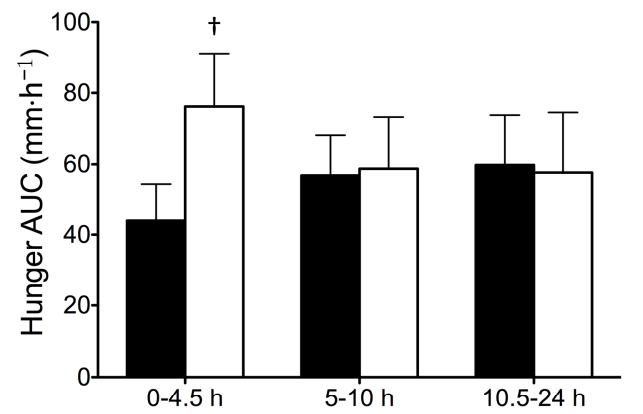
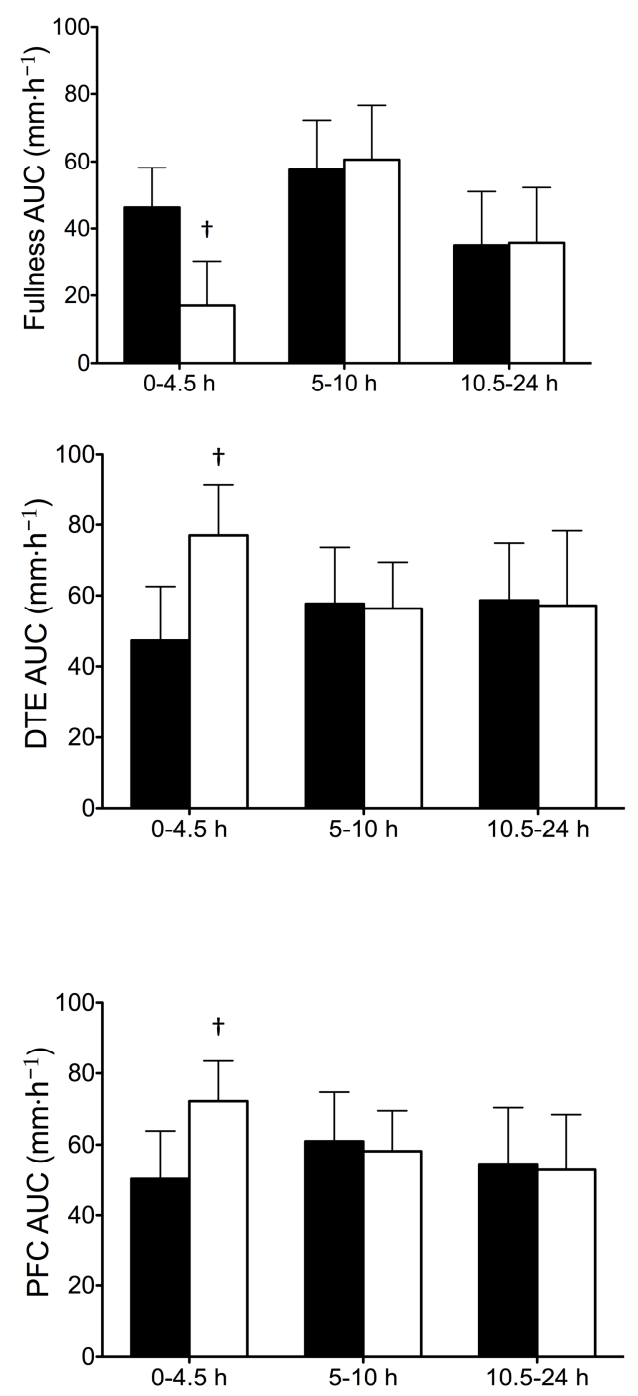
A

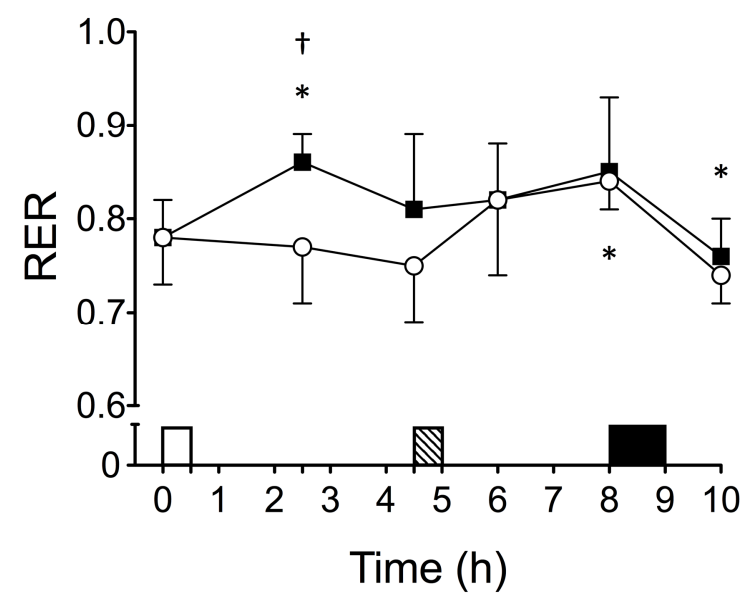

B

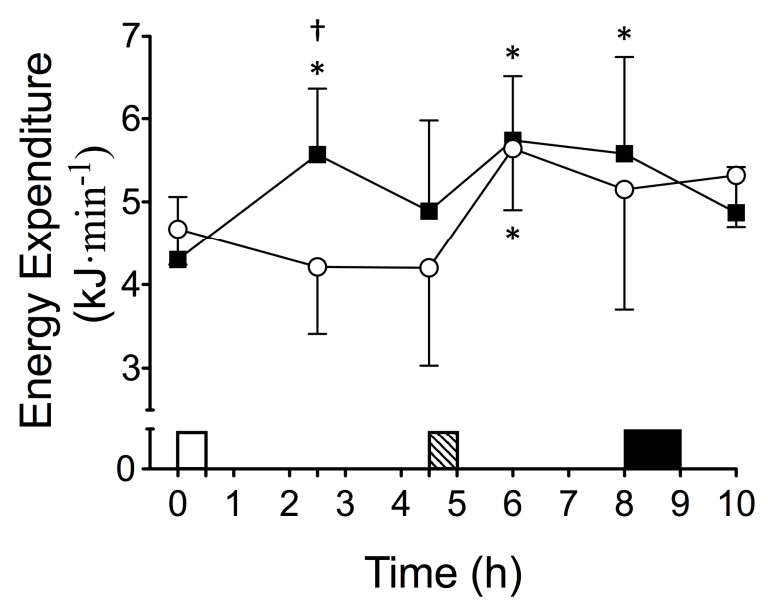




\section{Highlights}

- Appetite responses to breakfast omission/ consumption were compared

- Lunch and dinner intake were standardised

- Subjective appetite was not different between trials after lunch

- GLP-1 1-36 and acylated ghrelin were not different between trials after lunch

- The effects of breakfast omission appear transient and do not extend beyond lunch 